\title{
BMJ Open A retrospective cohort study of oral anticoagulant treatment in patients with acute coronary syndrome and atrial fibrillation
}

\author{
Linlin Mai, ${ }^{1}$ Yu Wu, ${ }^{1}$ Jianjing Luo, ${ }^{1,2}$ Xinyue Liu, ${ }^{1}$ Hailan Zhu, ${ }^{1}$ Haoxiao Zheng, ${ }^{1}$ \\ Guoquan Liang, ${ }^{2}$ Yan Zhang, ${ }^{1}$ Yuli Huang ${ }^{1}$
}

To cite: Mai L, Wu Y, Luo J, et al. A retrospective cohort study of oral anticoagulant treatment in patients with acute coronary syndrome and atrial fibrillation. BMJ Open 2019;9:e031180. doi:10.1136/ bmjopen-2019-031180

- Prepublication history for this paper is available online. To view these files, please visit the journal online (http://dx.doi org/10.1136/bmjopen-2019031180).

LM, YW and JL contributed equally.

Received 20 April 2019 Revised 25 August 2019 Accepted 29 August 2019

\section{Check for updates}

\section{(c) Author(s) (or their} employer(s)) 2019. Re-use permitted under CC BY-NC. No commercial re-use. See rights and permissions. Published by BMJ.

${ }^{1}$ Department of Cardiology, Shunde Hospital, Southern Medical University (The first people's hospital of Shunde), Foshan, China

${ }^{2}$ Department of Cardiology, The Second Hospital of Zhaoqing, Zhaoqing, China

Correspondence to

Dr Yuli Huang;

hyuli821@smu.edu.cn

\section{ABSTRACT}

Objective To examine the real-world patterns of oral anticoagulant (OAC) therapy in patients with acute coronary syndrome (ACS) and atrial fibrillation (AF) in Southern China undergoing percutaneous coronary intervention $(\mathrm{PCl})$ and determine the clinical characteristics associated with OAC prescription.

Design A retrospective cohort study.

Setting This study was conducted in the Shunde Hospital, Southern Medical University and the second hospital of Zhaoging, China, from January 2013 to 31 December 2018.

Participants Patients were aged $\geq 18$ years, hospitalised for ACS and received PCI treatment.

Outcome measures AF was diagnosed based on an ECG recording or a Holter monitor. Prescription of OACs and antiplatelets were determined from the discharge medication list.

Results A total of 3612 patients with ACS were included: $286(7.9 \%)$ were diagnosed with AF, including $45(1.2 \%)$ with paroxysmal AF, 227 (6.3\%) with persistent/permanent AF and 14 (0.4\%) with unclassified AF. Although $95.5 \%$ of patients with $\mathrm{AF}$ were at high risk $\left(\mathrm{CHA}_{2} \mathrm{DS}_{2}\right.$-VASc score $\geq 2$ ) of stroke, only $21.7 \%$ of them were discharged on OACs $(10.5 \%$ received warfarin and $11.2 \%$ received nonvitamin $\mathrm{K}$ antagonist OACs). Patients with pre-admission use of OAC, a HAS-BLED score $<3$, with persistent/ permanent $A F$ were more likely to receive $O A C$ treatment at discharge.

Conclusion We found that approximately $8 \%$ of patients who underwent $\mathrm{PCI}$ during ACS hospitalisation also demonstrated AF. Anticoagulant therapy was greatly underused. Patients with paroxysmal AF and an increased risk of bleeding were less likely to receive anticoagulant treatment. Further efforts should be made to increase the adherence to guideline recommendations for OACs.

\section{INTRODUCTION}

Atrial fibrillation (AF) is the most common arrhythmia worldwide. ${ }^{1}$ It is associated with a fourfold to fivefold increased risk of ischaemic stroke. ${ }^{2}{ }^{3}$ Known or new-onset AF is a common comorbidity in patients with acute coronary syndrome (ACS). It has been reported that $2 \%-21 \%$ of patients with ACS

\section{Strengths and limitations of this study}

- This is the first study to document the current real-world patterns of anticoagulation therapy in managing patients with acute coronary syndrome (ACS) and atrial fibrillation (AF) in Southern China.

- All the patients were with documented AF and received drug-eluting stent implantation.

- The present study highlights further efforts should be made to improve the adherence to guideline recommendations for oral anticoagulant treatment among patients with ACS and AF.

- Data were obtained from two large hospitals in Southern China and do not represent the current treatment status in other regions.

have a history of AF. ${ }^{4}$ Patients with ACS and AF have a poor prognostic outcome, including a higher risk of stroke. ${ }^{5-7}$ Antithrombotic treatment with oral anticoagulants (OACs), such as warfarin or non-vitamin $\mathrm{K}$ antagonist oral anticoagulants (NOACs), is a cornerstone in the prevention of ischaemic stroke in patients with $\mathrm{AF}^{8}{ }^{9}$ However, for patients with AF presenting with acute myocardial infarction (AMI) or coronary artery disease, undergoing percutaneous coronary intervention (PCI), it poses a great challenge with regard to the management of antithrombotic therapy. ${ }^{10}$ These patients need dual antiplatelet therapy (DAPT) to reduce the risk of subsequent myocardial infarction and stent thrombosis, and OACs treatment to prevent the risk of stroke. ${ }^{11}$

Although academic guidelines recommend that a combination of OACs and DAPT should be initiated in these patients and then subsequently switched to single antiplatelet agent combined with OACs, ${ }^{12} 13$ OACs have been largely underused in real-world clinical practice. ${ }^{14-19}$ However, NOACs have not been applied in most reported studies. ${ }^{14-19}$ 
Recently, there has been a significant price drop in NOACs and more evidence concerning the safety of these agents compared with warfarin. These factors may lead to greater use of NOACs instead of warfarin in patients at higher risk of bleeding, including those undergoing concomitant antiplatelet treatment. However, the prevalence of antithrombotic therapy in Chinese patients with ACS and AF has not been explored after the introduction of NOACs. Therefore, the current study was undertaken to examine current real-world patterns of OAC therapy in managing patients with ACS and AF in Southern China undergoing PCI.

\section{METHODS}

\section{Study population}

This was a retrospective cohort study conducted in the Shunde Hospital, Southern Medical University and the second hospital of Zhaoqing, China, from January 2013 to 31 December 2018.

We reviewed the medical records of patients aged $\geq 18$ years who were hospitalised for ACS and received PCI treatment. ACS was defined as ST-segment elevation myocardial infarction (STEMI), non-ST-segment elevation myocardial infarction (NSTEMI) or unstable angina (UA). STEMI was diagnosed based on elevated levels of biomarkers for myocardial necrosis (including troponin $\mathrm{T}$, troponin I or creatine kinase muscle/brain), with ST-segment elevation of $1 \mathrm{~mm}$ or more in at least two contiguous ECG leads, ${ }^{20}$ whereas NSTEMI was defined as ST-segment depression of $\geq 1 \mathrm{~mm}$. Patients with typical ischaemic symptoms and no elevation in biomarkers for myocardial necrosis, with or without ECG changes were classified as having $\mathrm{UA}{ }^{21} \mathrm{AF}$ was diagnosed using an ECG recording or a Holter monitor. For patients with length of hospital stay $\geq 7$ days, those with AF lasting $<7$ days were classified as having paroxysmal $\mathrm{AF},{ }^{1}$ and were otherwise classified as having persistent/permanent AF. In patients with no prior history of $\mathrm{AF}$ and with length of hospital stay $<7$ days, those with AF were defined as unclassified. All of the patients received coronary angiography and PCI. We excluded those with rheumatic heart disease or mechanical heart valves, death during hospitalisation or were transferred out within 3 days, or without discharge medication list available.

\section{Risk stratification and anticoagulation treatment}

Baseline characteristics including age, sex, smoking, history of hypertension, diabetes, dyslipidaemia, chronic kidney disease, previous stroke/transient ischaemic attack (TIA), history of AF and pre-admission use of OAC, ACS type, Killip classification were collected via the hospital medical record. Blood biochemical measurements, such as fasting plasma glucose, high-density lipoprotein cholesterol, total cholesterol and triglyceride levels were measured using an automated biochemical analyser. Estimated glomerular filtration rate was calculated using the modified Modification of Diet in Renal Disease equation adapted for Chinese. ${ }^{22}$

We used the $\mathrm{CHA}_{2} \mathrm{DS}_{2}$-VASc score to evaluate the risk of stroke (congestive heart failure, hypertension, age $\geq 75$ years (doubled), diabetes mellitus, history of stroke/ TIA (doubled), vascular disease, age 65-75 years and female sex). The risk of bleeding was evaluated using the HAS-BLED score (hypertension, abnormal renal/ liver function, history of stroke, history of bleeding, labile internationally normalised ratio, age $>65$ years, non-steroidal anti-inflammatory drugs or alcohol abuse). ${ }^{12}$ Because data concerning the time in therapeutic range for warfarin was not available, we defined the labile internationally normalised ratio as 'none' and 0 points were given to all patients when calculating the HAS-BLED score.

Prescription of warfarin, NOACs, aspirin and clopidogrel was determined from the discharge medication list. In the hospitals participating in the current study, rivaroxaban and dabigatran were the two types of NOAC available. Standard dosages of NOACs were defined as rivaroxaban $20 \mathrm{mg}$ /day or dabigatran $150 \mathrm{mg}$ two times per day for patients with creatinine clearance $\geq 50 \mathrm{~mL} /$ min, and rivaroxaban $15 \mathrm{mg}$ /day or dabigatran $110 \mathrm{mg}$ two times per day for creatinine clearance of $30-49 \mathrm{~mL} /$ min. ${ }^{23} 24$ Any daily dosages less than this range were defined as reduced dosages.

\section{Statistical analysis}

Patients with AF were divided into two groups based on whether they received OAC treatment or not, at discharge. Baseline characteristics, including $\mathrm{CHA}_{2} \mathrm{DS}_{2}-$ VASc score, HAS-BLED scores and antiplatelet therapy were examined. Continuous variables are presented as median (IQR) or mean (SD), as appropriate. Categorical variables are expressed as number (percentages). Continuous variables were compared using the Wilcoxon rank-sum test or Student's t-test after testing for normality using the Kolmogorov-Smirnov test. Categorical variables were compared using the $\chi^{2}$ or Fisher's exact test, as appropriate.

Multiple logistic regression models were used to examine the association between baseline characteristics and OAC treatment at discharge. Patients without $\mathrm{OAC}$ treatment were used as the reference. The variables adjusted in the multi-variable model were as follows: sex, age ( $\geq 65$ vs $<65$ years), diabetes, hypertension, dyslipidaemia, history of stroke, abnormal renal/liver function, non-steroidal anti-inflammatory drugs or alcohol abuse, history of bleeding, smoking status, type of ACS (UA or myocardial infarction), cardiac function (Killip classification III-IV vs I-II), type of AF (paroxysmal or persistent/ permanent) and pre-admission use of OAC. We further set the $\mathrm{CHA}_{2} \mathrm{DS}_{2}$-VASc score and HAS-BLED score as independent factors in the model while their individual components (age, sex, cardiac function, diabetes, hypertension, history of stroke, and history of bleeding) were not included to avoid over-adjustment. Adjusted ORs and 
corresponding $95 \%$ CIs are presented. All the statistical analysis was performed using SPSS V.20.0 (SPSS, Chicago, IL, USA). All comparisons are two-sided, with statistical significance defined as $\mathrm{p}<0.05$.

\section{Patient and public involvement}

Patients and the general public were not involved in the design and conception of this study.

\section{RESULTS}

\section{Baseline characteristics}

We reviewed 3813 electronic medical records of patients aged $\geq 18$ years, who were hospitalised for ACS and received PCI treatment from January 2013 to December 2018. After excluding 121 patients who died or were transferred out during hospitalisation, and 76 patients without a discharge medication list, 4 patients with mechanical heart valves, a total of 3612 patients were included in this study.

All of the patients received coronary angiography and drug-eluting stent implantation, 1393 of them (38.6\%) presented with AMI and received emergent PCI treatment, 2219 of them $(61.4 \%)$ were diagnosed with UA and received PCI during the index hospitalisation after carefully non-invasive examination.

Among all the included patients, 286 (7.9\%) were diagnosed with AF; 45 of these (1.2\%) had paroxysmal AF, 227 (6.3\%) had persistent/permanent AF and $14(0.4 \%)$ with unclassified AF. According to the hospital medical record, 48 patients were with document history of AF and $26(54.2 \%)$ of them were received OAC therapy prior to admission. Compared with those without AF, patients with $\mathrm{ACS}$ and AF were older and more likely to be women, with a higher prevalence of hypertension, diabetes and cardiac dysfunction, previous stroke/TIA, and higher mean $\mathrm{CHA}_{2} \mathrm{DS}_{2}$-VASc and HAS-BLED scores (all $\mathrm{p}<0.01$, table 1).

\section{Antithrombotic therapy}

The antithrombotic treatment regimens in patients with ACS and AF and patients with ACS without AF are presented in table 2. During the hospital stay, the ratio of parenteral anticoagulant treatment was higher in patients with AF compared with those without AF $(35.7 \%$ vs $21.0 \%, \mathrm{p}<0.01)$. The in-hospital use of antiplatelet agents, including aspirin and clopidogrel, were similar in patients with ACS and AF and patients with ACS and without AF (both $\mathrm{p}>0.05$ ). Prescription of OACs in patients with AF was low $(\mathrm{n}=85,29.7 \%)$; 38 of them received warfarin $(13.3 \%)$ and 47 of them received NOACs $(16.4 \%)$. In patients with NOACs treatment, 42 of them $(89.3 \%)$ received reduced dosages.

At hospital discharge, the use of antiplatelet agents was similar as in-hospital usage, and nearly $99 \%$ of patients with or without AF received DAPT. However, only 21.7\% of patients with $\mathrm{AF}(\mathrm{n}=62)$ were discharged on OACs, and $10.5 \%$ of them received warfarin and $11.2 \%$ received
Table 1 Baseline characteristics of patients with ACS and $\mathrm{AF}$ and patients with $\mathrm{ACS}$ and without $\mathrm{AF}$

\begin{tabular}{|c|c|c|}
\hline & $\begin{array}{l}\text { With } \\
\text { AF }(n=286)\end{array}$ & $\begin{array}{l}\text { Without AF } \\
(n=3326)\end{array}$ \\
\hline Age (year) & $68(58,76)^{\star \star}$ & $61(52,74)$ \\
\hline Sex (female (\%)) & $128(44.8)^{*}$ & $1285(38.6)$ \\
\hline $\mathrm{SBP}(\mathrm{mm} \mathrm{Hg})$ & $129.3 \pm 22.4^{\star *}$ & $125.4 \pm 23.9$ \\
\hline $\mathrm{DBP}(\mathrm{mm} \mathrm{Hg})$ & $78.5 \pm 18.4^{\star \star}$ & $76.2 \pm 17.9$ \\
\hline Hypertension (n(\%)) & $123(43.0)^{* *}$ & $1214(36.5)$ \\
\hline $\begin{array}{l}\text { Fasting plasma glucose } \\
(\mathrm{mmol} / \mathrm{L})\end{array}$ & $5.8 \pm 3.6^{*}$ & $5.4 \pm 3.2$ \\
\hline Diabetes mellitus ( $\mathrm{n}(\%))$ & $65(22.7)^{*}$ & $582(17.5)$ \\
\hline Serum creatinine ( $\mu \mathrm{mol} / \mathrm{L})$ & $96(65,124)$ & $92(63,136)$ \\
\hline eGFR $\left(\mathrm{mL} / \mathrm{min} / 1.73 \mathrm{~m}^{2}\right)$ & $62.2 \pm 25.1^{*}$ & $70.3 \pm 26.0$ \\
\hline Current smoker & $66(23.1)$ & $729(21.9)$ \\
\hline LDL-C (mmol/L) & $3.2 \pm 1.9$ & $3.0 \pm 1.8$ \\
\hline $\mathrm{HDL}-\mathrm{C}(\mathrm{mmol} / \mathrm{L})$ & $1.1 \pm 0.6$ & $1.0 \pm 0.5$ \\
\hline $\mathrm{TC}(\mathrm{mmol} / \mathrm{L})$ & $5.4 \pm 2.2$ & $5.3 \pm 2.2$ \\
\hline $\mathrm{TG}(\mathrm{mmol} / \mathrm{L})$ & $1.9 \pm 1.8$ & $1.8 \pm 1.6$ \\
\hline Dyslipidaemia(n(\%)) & $103(36.0)$ & $1173(35.3)$ \\
\hline Previous stroke/TIA (n(\%)) & $17(5.9)^{*}$ & $68(2.0)$ \\
\hline Previous CKD & $19(6.6)^{*}$ & 75 (2.3) \\
\hline Previous AF & $48(16.8)$ & - \\
\hline AMI $(n(\%))$ & $115(40.2)$ & $1278(42.5)$ \\
\hline UA (n(\%)) & $171(59.8)$ & $2048(57.5)$ \\
\hline $\begin{array}{l}\text { Killip classification III-IV } \\
(\mathrm{n}(\%))\end{array}$ & $84(29.4)^{* *}$ & $786(23.6)$ \\
\hline $\mathrm{CHA}_{2} \mathrm{DS}_{2}$-VASc score & $3.5 \pm 2.0^{\star \star}$ & $3.1 \pm 1.8$ \\
\hline HAS-BLED score & $3.0 \pm 1.6^{\star *}$ & $2.8 \pm 1.7$ \\
\hline Length of hospital stay & $7.6 \pm 2.9^{\star \star}$ & $7.1 \pm 2.6$ \\
\hline
\end{tabular}

Continuous variables are presented as median (IQR) or mean (SD). Categorical variables are expressed as number (percentages).

${ }^{\star} \mathrm{P}<0.05$ versus 'without $A F$ ' group. ${ }^{* *} \mathrm{P}<0.01$ versus 'without $A F$ ' group.

ACS, acute coronary syndrome; AF, atrial fibrillation; AMI, acute myocardial infarction; CKD, chronic kidney disease; DBP, diastolic blood pressure; eGFR, estimated glomerular filtration rate; HDL-C, high-density lipoprotein cholesterol; LDL-C, lowdensity lipoprotein cholesterol; SBP, systolic blood pressure; TC, total cholesterol; TG, triglyceride; TIA, transient ischaemic attack; UA, unstable angina.

NOACs (table 2). Similarly, in patients with NOACs treatment, $90.6 \%$ of them received reduced dosages.

\section{Determinants of OACs treatment at discharge}

We examined the association between baseline characteristics and OAC treatment at discharge. In all the included patients with $\mathrm{AF}$, only $4.5 \%$ were at moderate risk $\left(\mathrm{CHA}_{2} \mathrm{DS}_{2}-\mathrm{VASc}\right.$ score 1$)$, and $95.5 \%$ were at high risk $\left(\mathrm{CHA}_{2} \mathrm{DS}_{2}-\mathrm{VASc}\right.$ score $\left.\geq 2\right)$ of stroke. In terms of bleeding, $31.8 \%$ of the patients had a HAS-BLED score $\geq 3$, which was defined as a high risk of bleeding. The baseline 
Table 2 Antithrombotic treatment in patients with ACS and $\mathrm{AF}$ and patients with $\mathrm{ACS}$ and without $\mathrm{AF}$

\begin{tabular}{|c|c|c|}
\hline & $\begin{array}{l}\text { With AF } \\
(n=286)\end{array}$ & $\begin{array}{l}\text { Without AF } \\
(n=3326)\end{array}$ \\
\hline \multicolumn{3}{|l|}{ In-hospital } \\
\hline Aspirin (n(\%)) & $280(97.9)$ & 3291 (98.9) \\
\hline Clopidogre I(n(\%)) & $284(99.3)$ & $3318(99.8)$ \\
\hline $\begin{array}{l}\text { Parenteral anticoagulants } \\
{ }^{*}(\mathrm{n}(\%))\end{array}$ & $102(35.7)^{\star}$ & $698(21.0)$ \\
\hline OACs $(n(\%))$ & $85(29.7)^{\star}$ & $8(0.2)$ \\
\hline Warfarin (n(\%)) & $38(13.3)^{\star}$ & $3(0.1)$ \\
\hline NOACs (n(\%)) & $47(16.4)^{*}$ & $5(0.2)$ \\
\hline \multicolumn{3}{|l|}{ At discharge } \\
\hline Aspirin (n(\%)) & 281 (98.3) & 3289 (98.9) \\
\hline Clopidogrel (n(\%)) & $282(98.6)$ & 3316 (99.7) \\
\hline OACs $(n(\%))$ & $62(21.7)$ & $7(0.2)$ \\
\hline Warfarin (n(\%)) & 30 (10.5) & $3(0.1)$ \\
\hline NOACs (n(\%)) & $32(11.2)$ & $4(0.1)$ \\
\hline
\end{tabular}

Categorical variables are expressed as number (percentages). ${ }^{*} \mathrm{P}<0.01$ versus 'without AF' group.

ACS, acute coronary syndrome; AF, atrial fibrillation; NOACs, non-vitamin $\mathrm{K}$ antagonist oral anticoagulants; OACs, oral anticoagulants.

characteristics of the patients with AF received OACs or not at discharge are presented in table 3. As shown in table 4, patients with pre-admission use of OACs, a HAS-BLED score $<3$, with persistent/permanent AF were more likely to receive OACs treatment at discharge. However, neither a high risk of stroke nor other clinical characteristics were associated with OACs treatment.

\section{DISCUSSION}

There are three main findings in this study. First, the overall incidence of AF was $7.9 \%$ in patients with ACS and received PCI during hospitalisation. Second, although most patients with $\mathrm{AF}$ had a high risk of stroke, less than $30 \%$ received OACs treatment at discharge. Third, patients with pre-admission use of OACs, a lower risk of bleeding and persistent/permanent $\mathrm{AF}$ were more likely to receive anticoagulation therapy after PCI.

DAPT was recommended in patients with ACS who underwent PCI to reduce the risk of stent thrombosis. ${ }^{21}$ However, antiplatelet treatments have no clinical benefit in the treatment of AF. For patients with AF who undergo PCI, if the CHA2DS2-VASc score $\geq 2$, initial treatment with DAPT plus OACs (triple therapy) for at least 4 weeks is recommended under the current guidelines. ${ }^{112}$ However, such a 'triple therapy' strategy poses risks for bleeding and OACs are globally underused in clinical practice. ${ }^{14-19}$ The China acute myocardial infarction (CAMI) registry found that from 2013 to 2014, only $5.1 \%$ of patients with $\mathrm{ACS}$ and $\mathrm{AF}$ were treated using warfarin, and $1.7 \%$ were
Table 3 Characteristics of the patients with AF received $\mathrm{OAC}$ or not at discharge

\begin{tabular}{|c|c|c|}
\hline & $\begin{array}{l}\text { OAC } \\
\text { treatment } \\
(n=62)\end{array}$ & $\begin{array}{l}\text { Non-OAC } \\
\text { treatment } \\
(\mathrm{n}=224)\end{array}$ \\
\hline Age (year) & $69(57,77)$ & $68(59,76)$ \\
\hline Sex (female (\%)) & $30(48.4)$ & $98(43.8)$ \\
\hline Smoking $(\mathrm{n}(\%))$ & $16(25.8)$ & $50(22.3)$ \\
\hline Hypertension (n(\%)) & $32(51.6)$ & $91(40.6)$ \\
\hline Diabetes mellitus (n(\%)) & $19(30.6)$ & $46(20.5)$ \\
\hline Dyslipidaemia (n(\%)) & $20(32.3)$ & $83(37.1)$ \\
\hline Abnormal renal (n(\%)) & $5(8.1)$ & $14(6.3)$ \\
\hline Abnormal liver function (n(\%)) & $1(1.6)$ & $4(1.8)$ \\
\hline $\begin{array}{l}\text { Non-steroidal anti- } \\
\text { inflammatory drugs/alcohol } \\
\text { abuse }(\mathrm{n}(\%))\end{array}$ & $4(6.5)$ & $21(9.4)$ \\
\hline $\begin{array}{l}\text { Killip classification III-IV } \\
(\mathrm{n}(\%))\end{array}$ & $21(33.9)$ & $63(28.1)$ \\
\hline History of stroke (n(\%)) & $8(12.9)^{\star}$ & $9(4.0)$ \\
\hline History of bleeding (n(\%)) & $2(3.2)$ & $19(8.5)$ \\
\hline AMI $(n(\%))$ & $25(40.3)$ & $90(40.2)$ \\
\hline $\begin{array}{l}\mathrm{CHA}_{2} \mathrm{DS}_{2}-\text { VASc score } \geq 2 \\
(\mathrm{n}(\%))\end{array}$ & $61(98.4)$ & $212(94.6)$ \\
\hline HAS-BLED score $\geq 3(n(\%))$ & $12(19.4)^{\star \star}$ & 79 (35.3) \\
\hline $\begin{array}{l}\text { Persistent/permanent AF } \\
(\mathrm{n}(\%))\end{array}$ & $59(95.2)^{\star \star}$ & $168(75)$ \\
\hline $\begin{array}{l}\text { Pre-admission use of OAC } \\
(\mathrm{n}(\%))\end{array}$ & $19(30.6)^{\star \star}$ & $7(3.1)$ \\
\hline
\end{tabular}

${ }^{\star} \mathrm{P}<0.05$ versus 'non-OAC' group. ${ }^{* \star} \mathrm{P}<0.01$ versus 'non-OAC' group.

AF, atrial fibrillation; AMI, acute myocardial infarction; OAC, oral anticoagulant.

treated using both warfarin and DAPT. ${ }^{25}$ No NOACs were prescribed in patients with ACS and AF in the CAMI study. In the current study, we found that this situation was improved. Approximately $30 \%$ of patients with ACS and $\mathrm{AF}$ who underwent $\mathrm{PCI}$ received anticoagulation therapy at discharge, and half of them were prescribed with NOACs. This improvement may be caused by the accumulation of clinical research data, the availability of consensus guidelines for treatment, increased physician awareness of anticoagulation therapy and a price reduction in NOACs in China. However, it should be noted that OACs were still greatly underused.

Compared with warfarin, NOACs are more convenient to use, including advantages such as fixed dose regimens, no requirement for frequent blood monitoring, no food and drug restrictions and less risk of bleeding. ${ }^{2627}$ In the current study, we found that there was a substantially increased use of NOACs in Chinese patients during the past few years. This is consistent with data from the Danish nation-wide administrative registries, which found that by 2016, the use of NOACs in any combination with 


\begin{tabular}{|c|c|c|c|}
\hline Determinants & OR & $95 \% \mathrm{Cl}$ & $P$ value \\
\hline Sex (male vs female) & 0.90 & 0.44 to 1.84 & 0.77 \\
\hline Age ( $\geq 65$ vs $<65$ years) & 1.38 & 0.31 to 6.14 & 0.67 \\
\hline Smoking (yes vs no) & 1.07 & 0.26 to 4.40 & 0.93 \\
\hline Diabetes mellitus (yes vs no) & 1.48 & 0.80 to 2.74 & 0.21 \\
\hline Hypertension (yes vs no) & 1.35 & 0.43 to 4.24 & 0.61 \\
\hline Dyslipidaemia (yes vs no) & 0.73 & 0.21 to 2.54 & 0.62 \\
\hline $\begin{array}{l}\text { Abnormal renal (yes vs no) } \\
\text { Abnormal liver function (yes vs } \\
\text { no) }\end{array}$ & 1.25 & 0.55 to 2.84 & 0.59 \\
\hline $\begin{array}{l}\text { Non-steroidal anti-inflammatory } \\
\text { drugs/alcohol abuse (yes vs no) }\end{array}$ & 1.02 & 0.23 to 4.52 & 0.97 \\
\hline $\begin{array}{l}\text { Cardiac function (Killip } \\
\text { classification III-IV vs I-II) }\end{array}$ & 1.40 & 0.65 to 3.02 & 0.39 \\
\hline History of stroke (yes vs no) & 2.76 & 0.94 to 8.10 & 0.06 \\
\hline History of bleeding (yes vs no) & 0.80 & 0.23 to 2.78 & 0.73 \\
\hline Type of ACS (AMI vs UA) & 0.95 & 0.19 to 4.75 & 0.95 \\
\hline $\begin{array}{l}\text { Type of AF (persistent/permanent } \\
\text { vs paroxysmal) }\end{array}$ & 4.32 & 1.25 to 14.9 & 0.02 \\
\hline $\mathrm{CHA}_{2} \mathrm{DS}_{2}$-VASc score $(\geq 2 \mathrm{vs}<2)$ & 2.65 & 0.93 to 7.55 & 0.07 \\
\hline HAS-BLED score (<3 vs $\geq 3$ ) & 3.10 & 1.18 to 8.14 & 0.02 \\
\hline $\begin{array}{l}\text { Pre-admission use of OAC (yes } \\
\text { vs no) }\end{array}$ & 8.92 & 2.69 to 29.6 & 0.0003 \\
\hline
\end{tabular}

The variables adjusted in the multi-variable model were $s$ follows: sex, age ( $\geq 65 \mathrm{vs}<65$ years), diabetes, hypertension, history of stroke, history of bleeding, smoking status, type of ACS (UA or MI), cardiac function (Killip classification III-IV vs I-II) and type of AF (paroxysmal or persistent/permanent). Abnormal renal function was defined as chronic dialysis, renal transplant, serum creatinine $\geq 2.3 \mathrm{mg} / \mathrm{dL}$ (200 $\mu \mathrm{mol} / \mathrm{L})$; abnormal liver function was definced as chronic hepatic disease (eg, cirrhosis) or bilirubin $>2 \times$ upper limit of normal, in association with aspartate aminotransferase/alanine aminotransferase/ alkaline phosphatase $>3 \times$ upper limit normal. When $\mathrm{CHA}_{2} \mathrm{DS}_{2}-\mathrm{VASc}$ score and HAS-BLED score were included as independent factors in the model, the individual components (age, sex, cardiac function, diabetes, hypertension, history of stroke and history of bleeding) were not included to avoid over-adjustment.

ACS, acute coronary syndrome; $A F$, atrial fibrillation; $\mathrm{AMI}$, acute myocardial infarction;MI, myocardial infarction; UA, unstable angina.

antiplatelets was exceeding that of warfarin in combination with antiplatelets. ${ }^{28}$ However, in the current cohort, most patients (approximately 90\%) received a reduced dosage of NOACs, such as rivaroxaban $10 \mathrm{mg}$ /day. This may be driven primarily by the concern for increased risk of bleeding. It has been reported that in patients with $\mathrm{AF}$ and $\mathrm{AMI}$ and/or PCI, when in combination with DAPT, low-dose NOACs plus DAPT was associated with a lower rate of bleeding than a vitamin $\mathrm{K}$ antagonist plus DAPT. $^{29} 30$

In contrast with previous studies which showed that the use of OACs in patients with ACS and AF was influenced by neither stroke risk nor bleeding risk, ${ }^{18} 19$ our study found that patients with a HAS-BLED score $<3$ were more likely to receive OACs treatment at discharge. Furthermore, the number of patients treated with OACs at discharge $(21.7 \%)$ was significantly decreased than that during hospitalisation $(29.7 \%)$. These results suggest that physicians are still hesitant to prescribe 'triple therapy' because of concerns about the risk of bleeding. Both the American College of Cardiology (ACC)/American Heart Association (AHA)/Heart Rhythm Society (HRS) and the European Heart Rhythm Association (EHRA) / European Society of Cardiology (ESC) guidelines for the management of patients with $\mathrm{AF}$ have proposed a clear algorithm for the management of these patients. ${ }^{12}$ The most recently AHA/ACC/HRS guideline recommended that in patients with ACS and AF at increased risk of stroke, double therapy with P2Y12 inhibitors (clopidogrel) and low-dose rivaroxaban $15 \mathrm{mg}$ daily or dabigatran $150 \mathrm{mg}$ two times per day is reasonable to reduce the risk of bleeding, as compared with triple therapy. ${ }^{1}$ The EHRA/ESC guideline also proposed that dual therapy with OACs plus clopidogrel may be considered in patients with excessive bleeding risk and low thrombotic risk. ${ }^{12}$ However, providing optimal treatment is still a great challenge in real-world practice. In this study, we found that patients with ACS after PCI and AF were almost all treated with DAPT (nearly $99 \%$ of patients). However, OACs is greatly underused. These results pointed out a very 'awkward' situation, clinicians are concern about the risk of bleeding as well as stent thrombosis, so they choose to select DAPT but not double therapy with one P2Y12 inhibitor and OACs. These results showed that there are great gaps between real clinical practice and recommendations from the academic guidelines. Further efforts should be made to improve the adherence to guideline recommendations for OACs treatment among patients with ACS and AF.

The current study further found that patients with paroxysmal AF were less likely to receive OACs than those with persistent/permanent AF. This was not a surprise. The AHA/ACC/HRS guideline for the management of $\mathrm{AF}$ recommended that for patients with paroxysmal $\mathrm{AF}$, the need for anticoagulant therapy should be determined based on the risk of stroke, same with persistent AF. ${ }^{1}$ However, studies have shown that the risk of stroke in patients with paroxysmal $\mathrm{AF}$ is lower than that those with persistent/permanent $\mathrm{AF}^{31}{ }^{32}$ The benefit of anticoagulation in new-onset AF, occurring in the setting of an acute attack with ACS, acute pulmonary disease or sepsis, is associated with a higher risk of bleeding, but not with a reduced risk of ischaemic stroke. ${ }^{33}$ Therefore, for paroxysmal AF that occurs in the case of ACS, there is still much doubt about whether these patients need longterm anticoagulant therapy. Recently, a study showed that in patients with paroxysmal $\mathrm{AF}$, a greater burden of $\mathrm{AF}$ is associated with a higher risk of ischaemic stroke. ${ }^{34}$ Therefore, follow-up studies should be conducted to observe the re-occurrence of AF in the future.

There are some limitations in the current study. First, we did not evaluate the link between anticoagulant therapy and adverse events during hospitalisation and after discharge. Second, patient status was distinguished as paroxysmal $\mathrm{AF}$ or persistent/permanent $\mathrm{AF}$ based 
on medical records, so misclassifications cannot be totally avoided. Third, as a retrospective study, data were obtained from two large hospitals in Guangdong Province, China, and do not represent the current treatment status of other regions. Finally, we also found that some patients without $\mathrm{AF}$ were prescribed with OACs; however, the indications were unrecorded.

\section{CONCLUSION}

This study found that nearly $8 \%$ of patients who underwent PCI during ACS hospitalisation had AF. Although these patients were at an increased risk of stroke, anticoagulant therapy was greatly underused. Patients with paroxysmal AF and an increased risk of bleeding were less likely to receive anticoagulant treatment. The promotion of NOACs use can increase the treatment of anticoagulation in these patients.

Acknowledgements We thank Conn Hastings, PhD, from Liwen Bianji, Edanz Editing China (www.liwenbianji.cn/ac), for editing the English text during revision of this manuscript.

Contributors $\mathrm{YH}$ and LM conceptualised the study and designed the protocol. $\mathrm{YH}, \mathrm{YW}, \mathrm{JL}$ and $\mathrm{LM}$ analysed the data and drafted the manuscript. XL, $\mathrm{HZ}$ and $\mathrm{GL}$ collected the data. $\mathrm{YH}, \mathrm{HZ}$ and $\mathrm{YZ}$ revised the manuscript.

Funding The project was supported by Scientific Research Fund of Foshan, Guangdong, China (No: 2016AB003353), the National Natural Science Foundation of China (No: 81600239), the Science and Technology Innovation Project from Foshan, Guangdong (FSOAA-KJ218-1301-0006) and the Clinical Research Startup Program of Shunde Hospital, Southern Medical University (CRSP2019001). The funders had no role in the design and implementation of the study, in the collection, analysis and interpretation of the data, and in the preparation, review or approval of the manuscript.

Competing interests None declared.

Patient consent for publication Not required.

Ethics approval The study complied with the Declaration of Helsinki and was approved by the institutional review board central committee at Shunde Hospital, Southern Medical University, China. As this was a retrospective analysis, patients' informed consent was waived by the institutional review board.

Provenance and peer review Not commissioned; externally peer reviewed. Data availability statement Data are available upon reasonable request. Open access This is an open access article distributed in accordance with the Creative Commons Attribution Non Commercial (CC BY-NC 4.0) license, which permits others to distribute, remix, adapt, build upon this work non-commercially, and license their derivative works on different terms, provided the original work is properly cited, appropriate credit is given, any changes made indicated, and the use is non-commercial. See: http://creativecommons.org/licenses/by-nc/4.0/.

\section{REFERENCES}

1. January CT, Wann LS, Calkins H, et al. 2019 AHA/ACC/HRS focused update of the 2014 AHA/ACC/HRS guideline for the management of patients with atrial fibrillation: a report of the American College of Cardiology/American heart association Task force on clinical practice guidelines and the heart rhythm Society. J Am Coll Cardiol 2019;74:104-32.

2. Pokorney SD, Gersh BJ, Ahmad A, et al. Stroke prevention in atrial fibrillation: closing the gap. Am Heart J 2019;210:29-38.

3. Rohla M, Weiss TW, Pecen L, et al. Risk factors for thromboembolic and bleeding events in anticoagulated patients with atrial fibrillation: the prospective, multicentre observational PREvention oF thromboembolic events - European Registry in Atrial Fibrillation (PREFER in AF). BMJ Open 2019;9:e022478.
4. Jabre P, Roger VL, Murad MH, et al. Mortality associated with atrial fibrillation in patients with myocardial infarction: a systematic review and meta-analysis. Circulation 2011;123:1587-93.

5. Cordero A, Rodriguez-Mañero M, García-Acuña JM, et al. Incidence and predictors of stroke in patients discharged with the diagnosis of acute coronary syndrome. Int J Cardiol 2019;276:20-5.

6. Johnson V, Schmitt J. A chicken or egg dilemma: patients with atrial fibrillation and poor prognostic outcome in acute coronary syndrome. Rev Esp Cardiol 2019;72:367-8.

7. El-Battrawy I, Borggrefe M, Akin I. Atrial fibrillation as a risk factor for worse outcome in acute coronary syndrome. Int J Cardiol 2017;246:53.

8. Han TS, Fry CH, Fluck D, et al. Anticoagulation therapy in patients with stroke and atrial fibrillation: a registry-based study of acute stroke care in Surrey, UK. BMJ Open 2018;8:e022558.

9. Huang X, Chen Y, Xiao J, et al. Electrophysiological characteristics and catheter ablation of symptomatic focal premature atrial contractions originating from pulmonary veins and non-pulmonary veins. Clin Cardiol 2018;41:74-80.

10. Ferreiro JL, Gómez-Hospital JA. Antithrombotic therapy after acute coronary syndromes in patients with atrial fibrillation: Shouldn't we pay more attention to the risk of ischemic and thromboembolic events? Int J Cardiol 2019;276:38-9.

11. Neumann F-J, Sousa-Uva M, Ahlsson A, et al. 2018 ESC/ EACTS guidelines on myocardial revascularization. Eur Heart $J$ 2019;40:87-165.

12. Lip GYH, Collet J-P, Haude M, et al. 2018 joint European consensus document on the management of antithrombotic therapy in atrial fibrillation patients presenting with acute coronary syndrome and/ or undergoing percutaneous cardiovascular interventions: a joint consensus document of the European heart rhythm association (EHRA), European Society of cardiology Working group on thrombosis, European association of percutaneous cardiovascular interventions (EAPCI), and European association of acute cardiac care (ACCA) endorsed by the heart rhythm Society (HRS), AsiaPacific heart rhythm Society (APHRS), Latin America heart rhythm Society (LAHRS), and cardiac arrhythmia Society of southern Africa (CASSA). Europace 2019;21:192-3.

13. Steffel J, Verhamme P, Potpara TS, et al. The 2018 European heart rhythm association practical guide on the use of non-vitamin $\mathrm{K}$ antagonist oral anticoagulants in patients with atrial fibrillation: Executive summary. Europace 2018;20:1231-42.

14. Chamberlain AM, Gersh BJ, Mills RM, et al. Antithrombotic strategies and outcomes in acute coronary syndrome with atrial fibrillation. Am J Cardiol 2015;115:1042-8.

15. Lopes RD, Li L, Granger CB, et al. Atrial fibrillation and acute myocardial infarction: antithrombotic therapy and outcomes. Am J Med 2012;125:897-905.

16. Rohla M, Vennekate CK, Tentzeris I, et al. Long-term mortality of patients with atrial fibrillation undergoing percutaneous coronary intervention with stent implantation for acute and stable coronary artery disease. Int J Cardiol 2015;184:108-14.

17. Guimarães PO, Zakroysky P, Goyal A, et al. Usefulness of antithrombotic therapy in patients with atrial fibrillation and acute myocardial infarction. Am J Cardiol 2019;123:12-18.

18. Nelson JA, Vavalle JP, May CH, et al. Warfarin use and long-term outcomes in patients with acute myocardial infarction and atrial fibrillation. J Thromb Thrombolysis 2014;37:331-7.

19. Lopes RD, Starr A, Pieper CF, et al. Warfarin use and outcomes in patients with atrial fibrillation complicating acute coronary syndromes. Am J Med 2010;123:134-40.

20. China Society of Cardiology of Chinese Medical Association Editorial Board of Chinese Journal of Cardiology. [Guideline on the diagnosis and therapy of ST-segment elevation myocardial infarction]. Zhonghua Xin Xue Guan Bing Za Zhi 2015;43:380-93.

21. Roffi M, Patrono C, Collet J-P, et al. 2015 ESC guidelines for the management of acute coronary syndromes in patients presenting without persistent ST-segment elevation: Task force for the management of acute coronary syndromes in patients presenting without persistent ST-segment elevation of the European Society of cardiology (ESC). Eur Heart J 2016;37:267-315.

22. Ma Y-C, Zuo L, Chen J-H, et al. Modified glomerular filtration rate estimating equation for Chinese patients with chronic kidney disease. J Am Soc Nephrol 2006;17:2937-44.

23. Mahmood M, Lip GYH. Nonvitamin K oral anticoagulants in patients with atrial fibrillation and severe renal dysfunction. Rev Esp Cardiol 2018;71:847-55.

24. Potpara TS, Ferro CJ, Lip GYH. Use of oral anticoagulants in patients with atrial fibrillation and renal dysfunction. Nat Rev Nephrol 2018;14:337-51. 
25. Dai Y, Yang J, Gao Z, et al. Atrial fibrillation in patients hospitalized with acute myocardial infarction: analysis of the China acute myocardial infarction (CAMI) registry. BMC Cardiovasc Disord 2017;17:2.

26. Geng Y-P, Lan D-H, Liu N, et al. Patient-eported treatment satisfaction with dabigatran versus warfarin in patients with Non-Valvular atrial fibrillation in China. Thromb Haemost 2018;118:1815-22.

27. Wu S, Xie S, Xu Y, et al. Persistence and outcomes of non-vitamin K antagonist oral anticoagulants versus warfarin in patients with nonvalvular atrial fibrillation. J Clin Nurs 2019;28:1839-46.

28. Sindet-Pedersen C, Staerk L, Lamberts M, et al. Use of oral anticoagulants in combination with antiplatelet(s) in atrial fibrillation. Heart 2018;104:912-20.

29. Sindet-Pedersen $C$, Lamberts $M$, Staerk L et al. Combining Oral Anticoagulants With Platelet Inhibitors in Patients With Atrial Fibrillation and Coronary Disease. J Am Coll Cardiol 2018;72:1790-800.
30. Gibson CM, Mehran R, Bode C, et al. Prevention of bleeding in patients with atrial fibrillation undergoing PCl. N Engl J Med 2016;375:2423-34.

31. Zhang W, Xiong Y, Yu L, et al. Meta-Analysis of stroke and bleeding risk in patients with various atrial fibrillation patterns receiving oral anticoagulants. Am J Cardiol 2019;123:922-8.

32. Ganesan AN, Chew DP, Hartshorne T, et al. The impact of atrial fibrillation type on the risk of thromboembolism, mortality, and bleeding: a systematic review and meta-analysis. Eur Heart $J$ 2016;37:1591-602.

33. Quon MJ, Behlouli H, Pilote L. Anticoagulant Use and Risk of Ischemic Stroke and Bleeding in Patients With Secondary Atrial Fibrillation Associated With Acute Coronary Syndromes, Acute Pulmonary Disease, or Sepsis. JACC Clin Electrophysiol 2018;4:386-93.

34. Go AS, Reynolds K, Yang J, et al. Association of burden of atrial fibrillation with risk of ischemic stroke in adults with paroxysmal atrial fibrillation: the KP-RHYTHM study. JAMA Cardiol 2018;3:601-8. 